\title{
MANAGEMENT OF INFECTED FRACTURE NON-UNION OF LONG BONES BY MASQUELET TECHNIQUE IN PATIENTS WITH BONE LOSS LESS THAN 4 CM
}

\author{
Bellary Mohammed Ghouse1, Koti Satish², Buchireddy Jayachandra Reddy³, Zeeshan Mujahid ${ }^{4}$
}

${ }_{1}^{1}$ Assistant Professor, Department of Orthopaedics, Government Medical College/ Government General Hospital, Ananthapuramu, Andhra Pradesh, India.

2Associate Professor, Department of Orthopaedics, Government Medical College/ Government General Hospital, Ananthapuramu, Andhra Pradesh, India.

3Professor, Department of Orthopaedics, Government Medical College/ Government General Hospital, Ananthapuramu, Andhra Pradesh, India.

${ }^{4}$ Senior Resident, Department of Orthopaedics, Government Medical College/ Government General Hospital, Ananthapuramu, Andhra Pradesh, India.

ABSTRACT
BACKGROUND
Management of infective non-union in long bone fractures is a demanding task. Infected non-union has been defined as a state of
failure of union and persistence of infection at fracture site for 9 months. Infective non-union of long bone fractures are associated
with problems like infection- osteomyelitis, multiple sinuses. shortening, limb length deformity and contractures.
Aim- This study has been carried out to compare the functional outcome of the management of infected non-union of long bone
fractures by Masquelet technique in patients with less than $4 \mathrm{~cm}$ bone loss.

\section{MATERIALS AND METHODS}

It was a prospective observational study. 40 patients who had infected non-unions (22 male and 18 female) admitted in Government General Hospital, Ananthapuramu, between May 2015 and June 2017 were included in this study. All patients were in age group of 20 to 50 yrs., and functional outcome was assessed by haematological investigations, time taken for reduction of infection, time for clinical union and average time taken for mobilisation.

\section{RESULTS}

Total 40 patients were treated, among them 22 were male and 18 were female. Average time taken for infection to subside was 7.63 weeks for males and 7.3 weeks for females. Average time taken for ambulation was 6.2 weeks for males and 8 weeks for females and average time taken for union clinically was 34.36 weeks for males and 37.2 weeks for females. Among the 40 patients 3 patients had non-union, 3 patients had re-infection, 3 patients had limb shortening and 2 patients had limp.

\section{CONCLUSION}

Modified Masquelet technique is a viable option for treatment of infected non-union of long bones. It helps in complete control of infection by slow eluting of antibiotic from antibiotic cement and rigid fixation helps in achieving early mobilisation and early clinical union compared to other modalities of treatment.

\section{KEY WORDS}

Infected Non-Union, Antibiotic Nail, Induced Membrane, Bone Cement, Cement Spacer, Masquelet Technique.

HOW TO CITE THIS ARTICLE: Ghouse BM, Satish K, Reddy BJ, et al. Management of infected fracture non-union of long bones by masquelet technique in patients with bone loss less than $4 \mathrm{~cm}$. J. Evolution Med. Dent. Sci. 2018;7(33):3715-3720, DOI: $10.14260 /$ jemds/2018/834

\section{BACKGROUND}

Management of infective non-union in long bone fractures is a demanding task. Infected non-union has been defined as a state of failure of union and persistence of infection at fracture site for 9 months. ${ }^{1}$ Infective non-union of long bone fractures are associated with problems like:

Infection- osteomyelitis, multiple sinuses. Shortening, limb length deformity and contractures. ${ }^{2}$

'Financial or Other Competing Interest': None.

Submission 27-05-2018, Peer Review 31-07-2018,

Acceptance 06-08-2018, Published 13-08-2018.

Corresponding Author:

Dr. Bellary Mohammed Ghouse,

D. No. 9-390,

Gulzarpet, Ananthapuramu,

Andhra Pradesh, India.

E-mail: drghouse11@gmail.com

DOI: $10.14260 /$ jemds $/ 2018 / 834$

\section{(c) (i) $\$$}

It is associated with lot of physical and mental trauma to patients and his family members. Various surgical methods have been used previously for management of long bone infected.

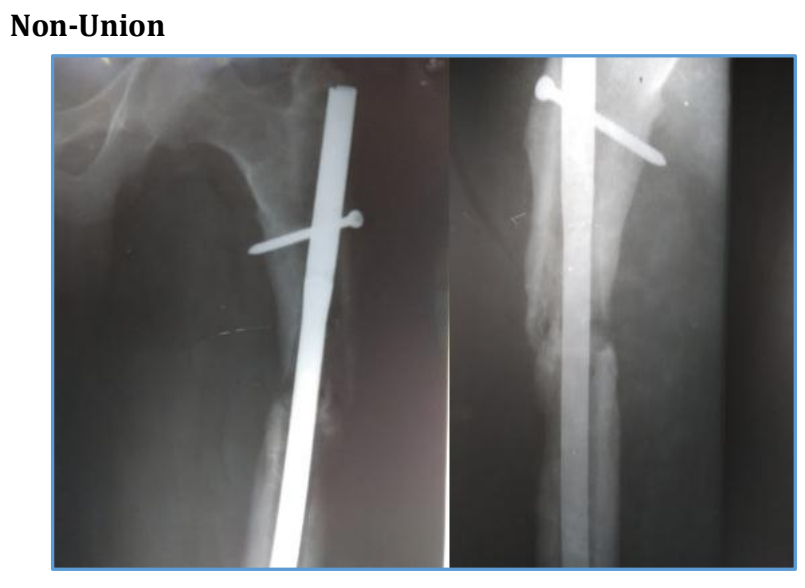

Infected Fracture of Non-Union of Long Bones 
Bone Transport is a well-established technique for the Management of Bone defects. ${ }^{3}$ This Procedure has a very high Complication Rate: Up to $\mathbf{8 0 \%}$ -

- The Ilizarov technique is the one commonly used to address intermediate and large bone defects. The technique is very demanding and patient's cooperation is critical. ${ }^{4}$

- There is no single current technique that is reliably successful in the management of infected non-union bone defects.

- The Masquelet technique does offer an alternative and a viable management strategy for large bone defects.

The Technique was developed in 1986 to Address Defects It can be safely used in irradiated or infected areas provided the membrane is formed around the defect to protect and vascularize the bone graft.

First treating of infection is the priority. So infection was treated with debridement and antibiotics and based on fracture it was fixed with internal fixation with plating or intramedullary nailing.

\section{Principle of Technique}

- The first stage is comprised of a radical debridement and a soft tissue repair, and the insertion of a polymethyl methacrylate (PMMA) cement spacer mixed with antibiotic into the bone defect along with an antibiotic coated intramedullary nail for stabilising the fracture.

- The second stage is performed 6 to 8 weeks later, when the definitive healing of soft tissue is acquired. The spacer is removed, but the membrane that is induced by the cement is left in place. ${ }^{5}$ The cavity is filled up by Morselized cancellous bone autograft harvested from the iliac crests along with a definitive fixation. ${ }^{6}$

\section{MATERIALS AND METHODS}

It was a prospective observational study. 40 patients who had infected non-union (22 male and 18 female) admitted in Government General Hospital, Ananthapuramu from May 2015 to June 2017 were included in this study and the study was evaluated after six weeks, three months and 12 months.

\section{Inclusive Criteria}

All patients in age group of 20 to 50 years and infected fractures of Diaphyseal and metaphyseal bone defects, predominantly of the lower extremity were included in this study. It was a prospective observational study.

After admission patient underwent haematological investigations like CBP, CRP, ESR and pus for culture and sensitivity were done to establish infection. X-ray of the involved bone to look for changes in bone like bone marrow haziness, periosteal reaction and sequestrum was done.

\section{Procedure/ First Stage}

Radical Debridement

It involves radical debridement of all infected and non-viable bone and interposed fibrous tissue. All devitalised tissue should be removed, which serves as a nidus for recurrence. ${ }^{7}$

- The margins of debridement should extend until viable bony edges are encountered, determined intraoperatively using the "paprika sign" (punctate bleeding).

\section{Preparation of Antibiotic-Impregnated Indigenous} Cement

After the surgical team had changed their gloves, the limb was re-draped before antibiotic-impregnated cement was prepared.

Antibiotic cement was prepared with $2 \mathrm{~g}$ of antibiotic and $40 \mathrm{~g}$ of PMMA cement. The antibiotics used were vancomycin and gentamicin or clindamycin. If more than $4 \mathrm{~g}$ of antibiotic is used, the cement becomes brittle. The antibiotic cement was kept in air for evaporation of the monomer.

\section{Placement of Antibiotic Impregnated Cement Spacer and Intramedullary Nail}

The role of the cement spacer is to avoid the collapse of the soft tissue into the bone defect and to maintain the dead space for the bone reconstruction. ${ }^{8}$

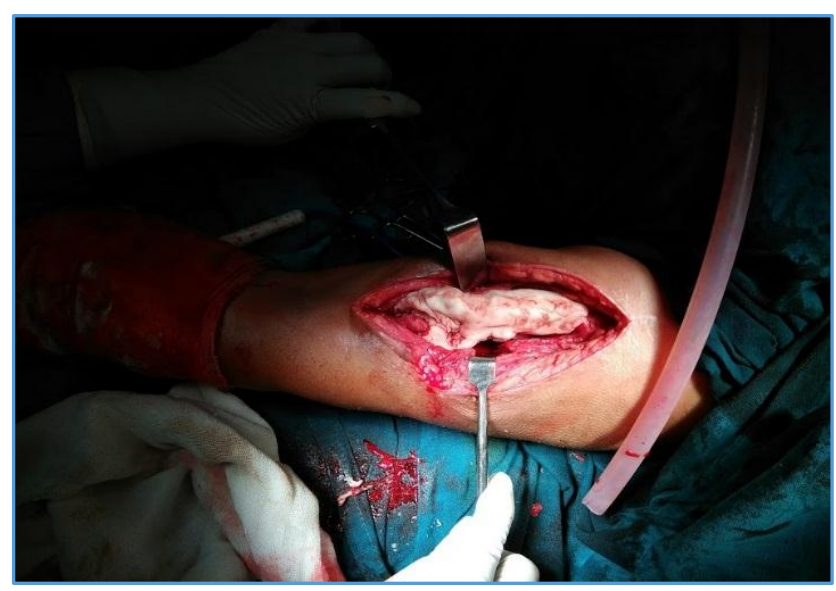

\section{Limb Stabilisation}

Following debridement stabilisation must be achieved to maintain length, alignment and rotation prior to insertion of the cement spacer. Choice of stabilizer depends on the site of the defect. For bone loss in the mid-diaphysis, an intramedullary nail offers stable fixation that allows early weight bearing. Because of more stable fixation and reduced rate of infection post debridement due to better antibiotics and wound care. ${ }^{9}$

- $\quad$ They also reduce the graft requirement and also prevent the central core of densely packed graft (unlikely to revascularize).

- To avoid biofilm formation and to create a complete induced membrane, it is advised that the implant should be completely covered with the antibiotic cement.

\section{Antibiotic-Cemented Nail Preparation}

- It is performed manually on a separate table taking all aseptic measures.

- $\quad$ K-nails (for cases with femur non-union) of diameter 2-3 $\mathrm{mm}$ thinner than the last reamer width were chosen.

- PMMA bone cement of $40 \mathrm{~g}$ was mixed with $2 \mathrm{~g}$ of vancomycin powder or clindamycin cap. Monomer solution was added to this powder and mixed until the material acquired viscous consistency. At the late liquid stage of the cement, antibiotic-impregnated cement was poured into $50 \mathrm{~mL}$ of syringe.

- $\quad$ The antibiotic cement was then applied uniformly over the NAIL and the cement was allowed to set. 
- The diameter of the cement nail was checked, excess cement was shaved off and the nail was re-rolled before the cement set.

Bone Cement is allowed to set for 15 mins Before Insertion to Prevent Cement Nail Debonding

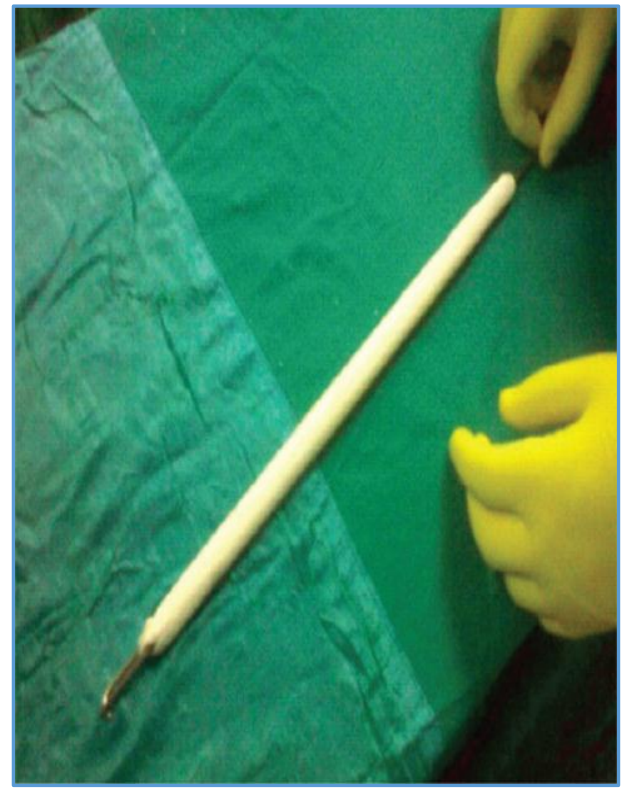

Placement of Antibiotic Nail with a Cement Spacer
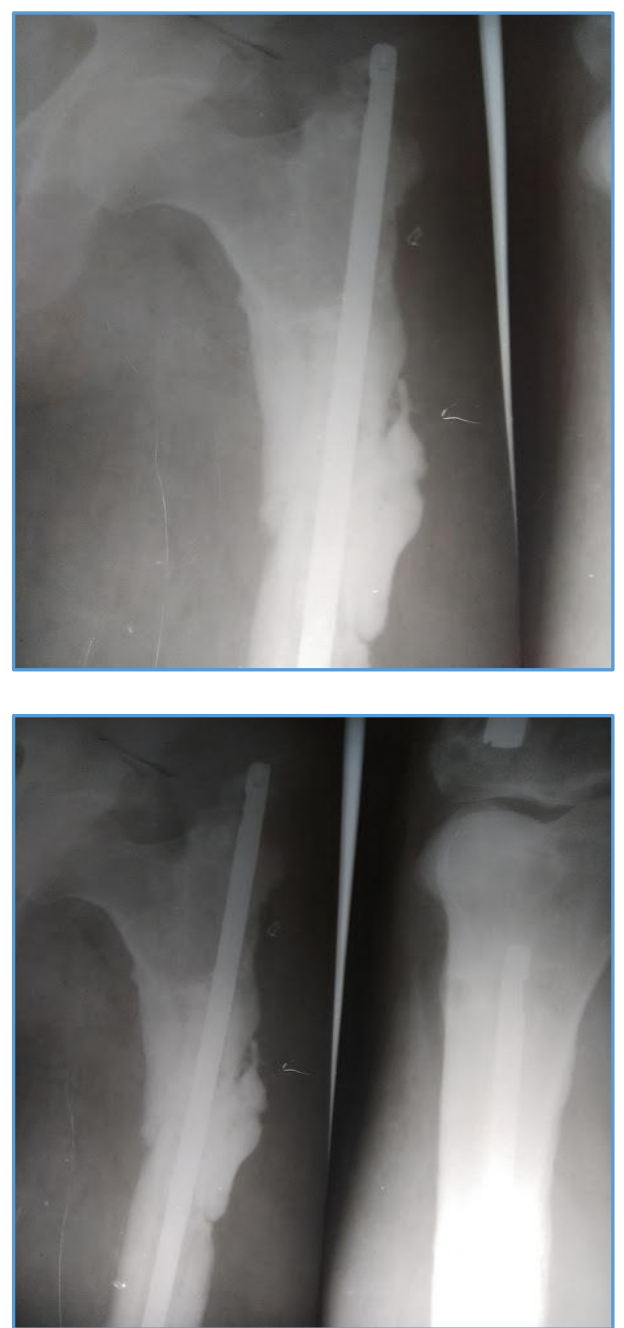

For optimal outcome, the cement spacer should fill the intramedullary canal and edges of surrounding viable bone to allow detaching small pieces of the ends of the bone when cement is removed and lifting it with a bit of the induced membrane at the second stage. 5

\section{Formation of Induction Membrane}

It forms around the bone cement. It is a living tissue that plays an important role in bone healing or union. The membrane serves a very critical function: The role of the cement spacer is-

1. To avoid the collapse of the soft tissue into the bone defect and to maintain the dead space for the bone reconstruction.

2. Protection of cancellous bone graft from the body's immune system. This prevents cancellous bone resorption.

\section{Induced Membrane}

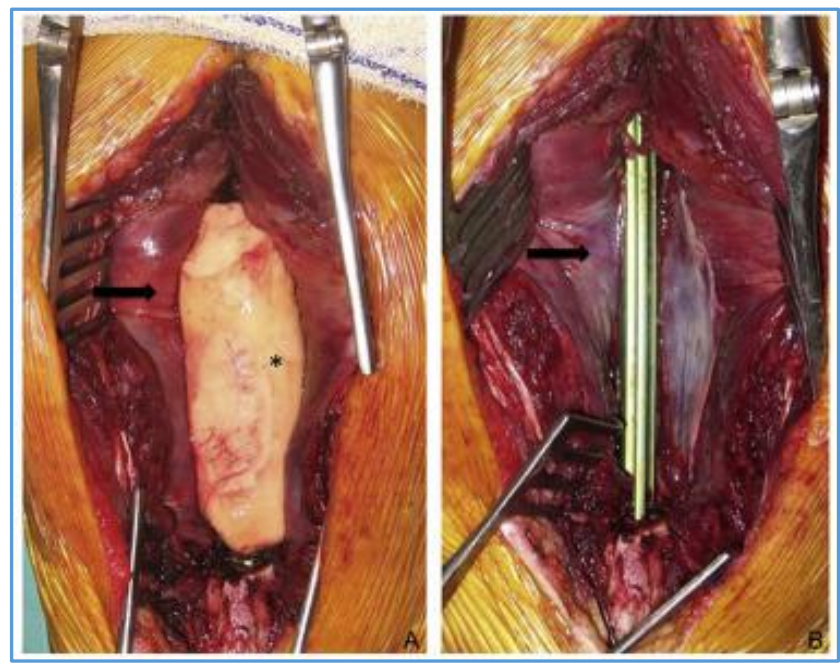

The bone cement provides additional support to the limb and maintain the defect.

\section{Production of Induced Membrane}

The induced membrane has been shown to-

- Act as a protective physical barrier by preventing bone autograft resorption.

- It acts as a Bioreactor by promoting healing.

Through revascularisation and growth factor secretion and by concentrating on Mesenchymal Stem Cells (MSC) with osteogenic properties.

\section{Second Stage/ Clearance of Infection}

Complete eradication of infection is a prerequisite to reconstruction of bone defects due to osteomyelitis (Stage 2 of the Masquelet technique).

- Levels of acute inflammatory markers, including CBP, CRP and ESR should be normal in patients lacking comorbidities.

- If there remains any doubt as to the presence of residual infection, then tissue specimens at the site of the segmental defect can be harvested for culture and pathology. 


\section{The Second Stage is a Biological One-}

1. The second stage of bone grafting was performed $4-12$ weeks after the first surgery.

2. The fracture is approached through the previous incision and careful dissection was performed down to the defect.

3. The biomembrane encapsulating the cement spacer is carefully incised.

4. Once exposed, the cement spacer is removed and the biomembrane capsule is irrigated to remove any residual debris.

5. Removal of antibiotic coated cemented K-nail and application of intramedullary interlocking nail. Acute docking at fracture site is supported with plate.

With the defect being open, bone graft is placed to fill the entire defect. Densely packing of the graft should be prevented, as it has been shown that tightly packed graft does not consolidate well.

On tight packing of the graft, while the peripheral graft seems to revascularize and ossify, the central core of graft remains unhealed and non-vascular.

After the bone graft is placed in the membrane, the soft tissues including the membrane are sutured close to the graft resulting in a containment chamber.

'Watertight' induced membrane chamber can be considered to be a complex bioreactor, continuously providing osteogenesis factors, cells as well as a blood supply for bone graft.

Induced membrane technique must be combined with stable fixation, as instability may lead to deformity or nonunion.

Once the defect is filled, the biomembrane is closed with absorbable suture

- The cancellous bone is capable of forming bone even without stress to the bone.

- The membrane secretes growth factors ${ }^{10}$; high concentration of VEGF and TGF Beta 1 were observed as early as the second week.

- $\quad$ BMP2 is at its highest level at the fourth week.

- Membrane extracts has been shown to stimulate bone marrow cell proliferation and differentiation to osteoblastic lineage in vitro.

- The membrane is richly vascularized in all its layers.

- The inner part (face to the cement) is a synovial like epithelium and the outer part is made of fibroblasts, myofibroblasts and collagen.

\section{Statistical Analysis}

The data was entered in Microsoft Excel 2007 and analysed using SPSS version 16.0 software. The descriptive statistical methods like mean, standard deviation, frequencies and proportion were used. Chi-square test was used for comparison of categorical variables and independent t-test for comparing means. A ' $p$ ' value of less than 0.05 was taken as significant.

\section{RESULTS}

Out of Total 40 patients treated for the management of infected non-union by masquelet technique in bone loss less than $4 \mathrm{~cm}$, among them 22 (55\%) were male, of which their mean age is 33.6 and sample standard deviation is 5.53 and among 18 (45\%) were female, of which their mean age is 34.5 and sample standard deviation is 5.10. And out of the 40 patients treated, the mean average time taken for infection to subside in males was 7.63 weeks with sample standard deviation of 1.17 and variance standard deviation of 1.385 and in females was 7.3 weeks with standard deviation of 1.28 and variance standard deviation of 1.64 .

The mean average haemoglobin levels for males was $11.09 \mathrm{~g} / \mathrm{dL}$ with sample standard deviation of 1.25 and variance standard deviation of 1.56 and for females it was $9.44 \mathrm{~g} / \mathrm{dL}$ with sample standard deviation of 1.65 and variance standard deviation of 2.73 .

The Mean Average time taken for ambulation was 6.2 weeks for males and 8 weeks for females. The Mean Average time taken for union clinically was 34.36 weeks for males with sample standard deviation of 2.93 and variance standard deviation of 8.62 and 37.2 weeks for females with sample standard deviation of 4.67 and variance standard deviation of 21.85 .

Out the 40 patients treated, among 22 males one patient (4.54\%) had non-union, two patients $(9.09 \%)$ had reinfection, 1 patient (4.54\%) had limb shortening and 1 patient (4.54\%) had limp and among 18 females two patients (11.11\%) had non-union, 1 patient (5.55\%) had reinfection, 1 patient (5.55\%) had limb shortening and 1 patient (5.55\%) had limp.

\begin{tabular}{|c|c|c|c|}
\hline Parameter & $\begin{array}{c}\text { Male } \\
(\mathbf{n = 2 2}) \mathbf{5 5 \%}\end{array}$ & $\begin{array}{c}\text { Female } \\
(\mathbf{n = 1 8}) \mathbf{4 5 \%}\end{array}$ & P value \\
\hline & \multicolumn{2}{|c|}{ Mean and SD } & \\
\hline Haemoglobin & $11.09 \pm 2.8$ & $9.44 \pm 3.15$ & $<0.001$ \\
\hline $\begin{array}{c}\text { Time taken for } \\
\text { subsiding infection }\end{array}$ & $7.63 \pm 1.17$ & $7.3 \pm 1.28$ & $<0.001^{*}$ \\
\hline $\begin{array}{c}\text { Time taken for } \\
\text { union }\end{array}$ & $34.36 \pm 2.93$ & $37.2 \pm 4.67$ & 0.019 \\
\hline Bone loss & $1.83 \pm 0.23$ & $1.99 \pm 0.15$ & $<0.001$ \\
\hline \multicolumn{4}{|c}{ Demographic Table } \\
\hline
\end{tabular}

\begin{tabular}{|c|c|c|c|}
\hline Complications & Male $(\mathrm{n}=22)$ & Female $(\mathrm{n}=18)$ & P value \\
\hline Re-infection & $2(0.09 \%)$ & $1(5.55 \%)$ & 0.514 \\
\hline Non-union & $1(4.54 \%)$ & $2(11.11 \%)$ & 0.028 \\
\hline Limp & $1(4.54 \%)$ & $1(11.11 \%)$ & 0.767 \\
\hline Limb shortening & $1(4.54 \%)$ & $2(11.11 \%)$ & 0.079 \\
\hline
\end{tabular}

Bone Graft Filled in the induced membrane of Bone defect stabilising with Nail and a Plate

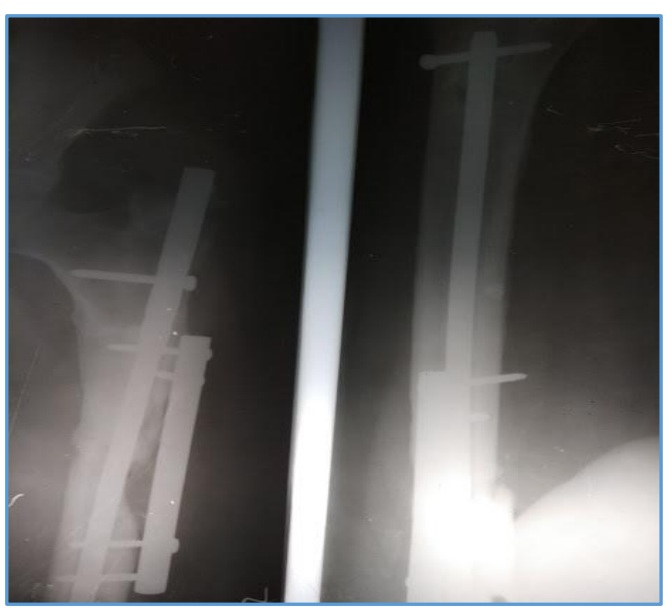




\section{After 3 Months}

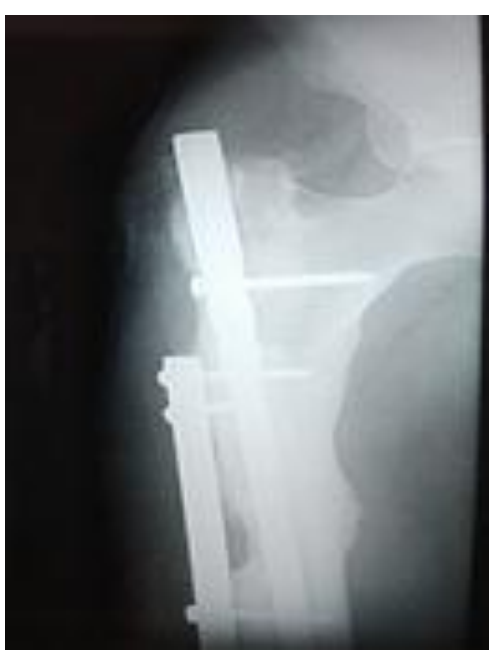

RESULTS

Before Intervention

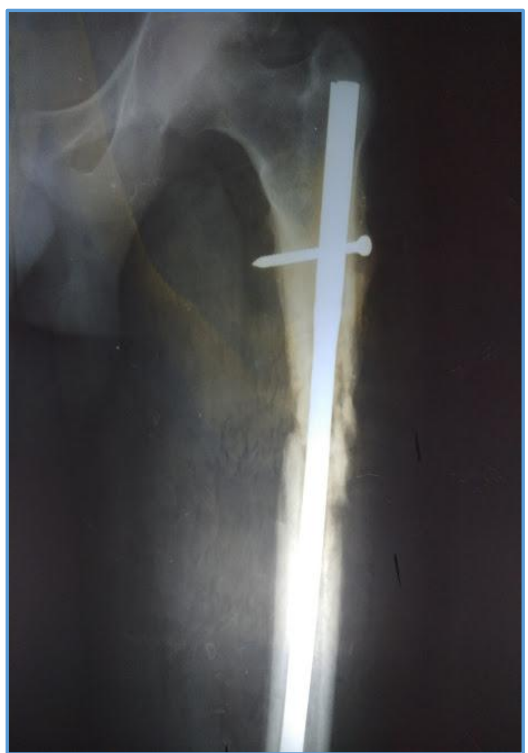

\section{After Intervention}

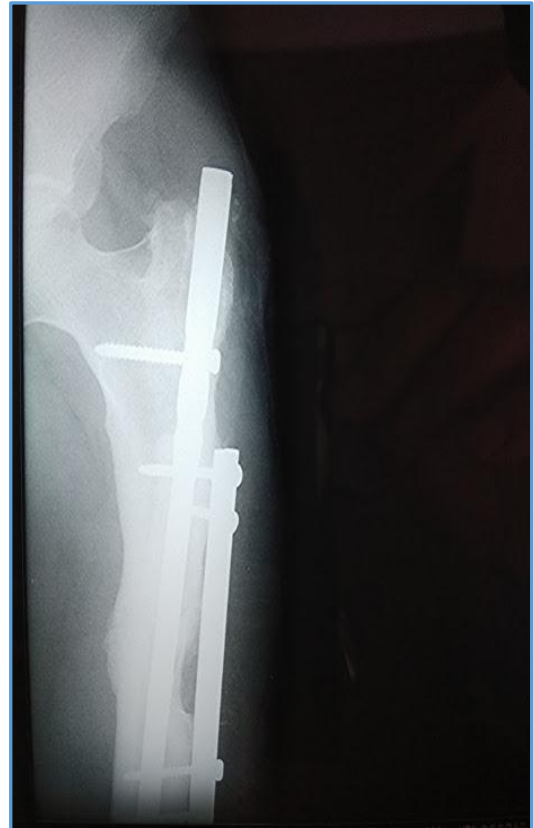

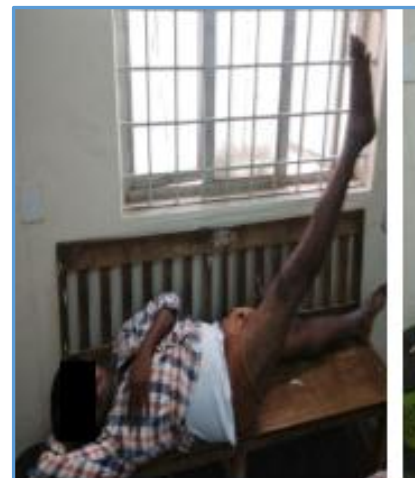
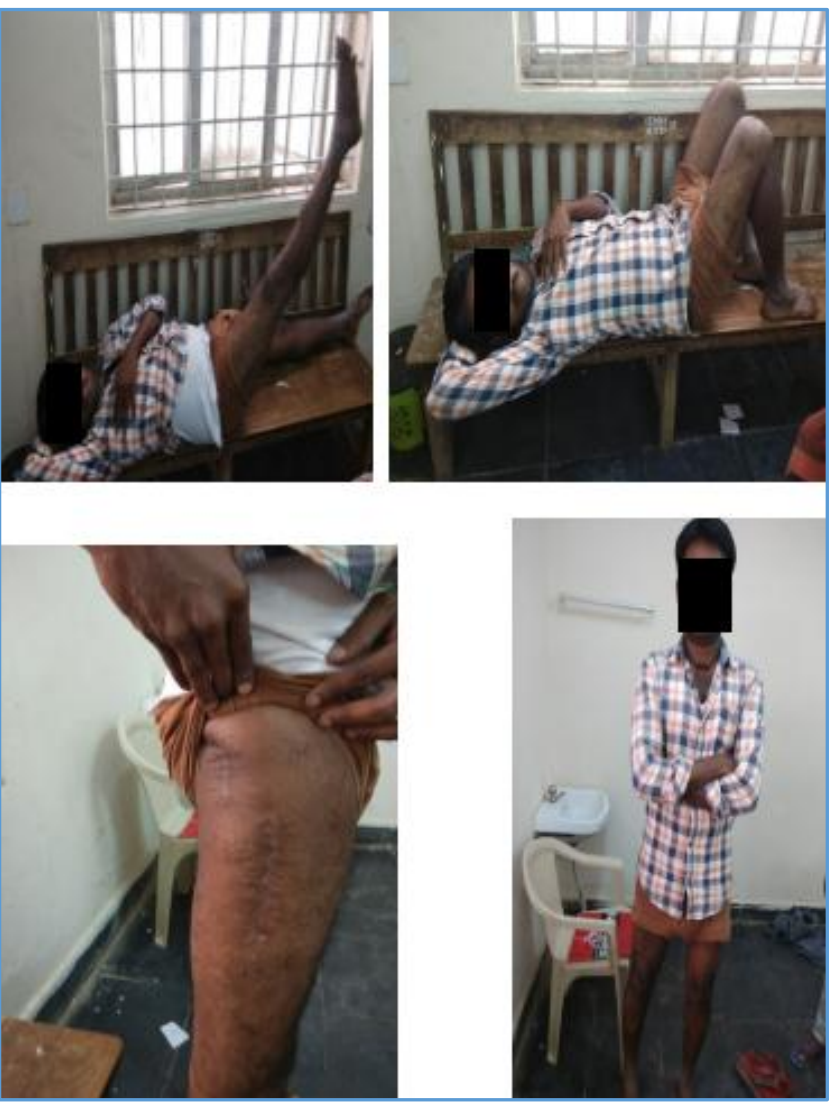

Management of Infected Non-Union of Humerus with Masquelet Technique

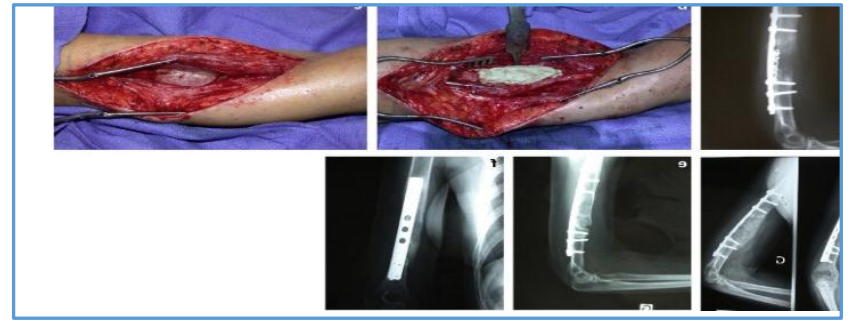

Infected Fracture Non-Union of Ulna
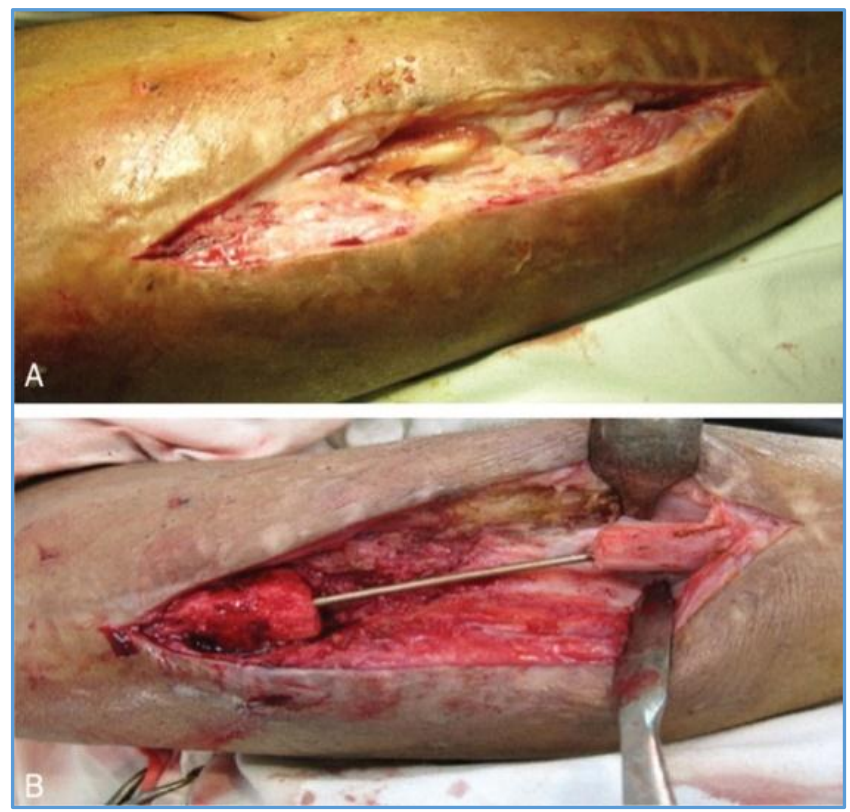


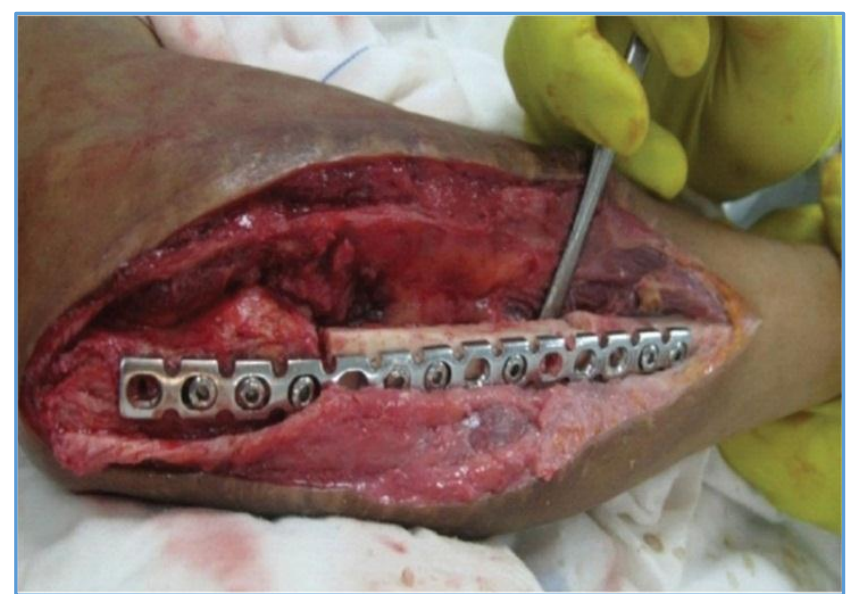

\section{DISCUSSION}

Thorough debridement, rigid fixation and antibiotic cement are the mainstay in treatment of infected non-union of bone. ${ }^{11} \mathrm{~A}$ variety of staged procedures have been described for infected non-union. Bone defects following debridement increases challenge to manage the case. In this study, our aim was to evaluate the results of Masquelet technique in management of infected non-union of long bones with bone loss less than $4 \mathrm{cms}$.

Among the 40 patients, males were $22(55 \%)$ and females were $18(45 \%)$ percent and the average age in males were 34 and in females it was 35 .

Union was achieved among 37 out of 40 patients. The union achieved was $92.5 \%$, which was near similar to results achieved by Rajesh Dhanasekharan et al.12

The average time taken for reduction of infection was 7.6 weeks in males and 7.3 weeks in females, which was similar to Dr. Ashok K Shyam et al,13 which was 6.1 weeks on average.

The total time taken for clinical union is 34.3 weeks in males and 37.2 weeks in females. After second stage procedure, it is 14 weeks in males and 16 weeks in females which was lesser than time taken in studies by Ashok $\mathrm{K}$ Shyam et al. The average time for mobilisation was 6.2 weeks in males and 8 weeks in females after second surgery.

The infection was controlled in 37 out of 40 cases, which was near similar to study done by Bhatia $\mathrm{C}$ et $\mathrm{al}^{14}$ and Rajesh Dhanasekhar et al.

The complication rates were also similar to studies.

The time for clinical union, average time for mobilisation and average bone loss were higher for females in this study and this can be due to low haemoglobin levels and lower strength levels and higher age group of females.

\section{CONCLUSION}

- Modified Masquelet technique is a viable option for treatment of infected non-union of long bones.

- It helps in complete control of infection by slowly eluting antibiotics from antibiotic cement.
- Induced membrane acts as a biological chamber keeping the cancellous graft together and prevents its resorption.

- The membrane promotes the vascularisation and the corticalization of the cancellous bone, even in badly vascularized bed like irradiated tissue.

- Membrane is considered an in situ delivery system for growth and osteoinductive factors (MC is BMP-2).

- And rigid fixation helps in achieving early mobilisation and clinical union compared with other modalities of treatment.

\section{REFERENCES}

[1] Struijs PA, Poolman RW, Bhandari M. Infected nonunion of the long bones. J Orthop Trauma 2007;21(7):507-11.

[2] Jain AK, Sinha S. Infected non-union of the long bones. Clin Orthop Relat Res 2005;(431):57-65.

[3] Green SA, Jackson JM, Wall DM, et al. Management of segmental defects by the llizarov intercalary bone transport method. Clin Orthop Relat Res 1992;(280):136-42.

[4] Aronson J. Limb lengthening, skeletal reconstruction and bone transport with the llizarov method. J Bone Joint Surg Am 1997;79(8):1243-58.

[5] Chandayammuri V, Hake M, Mauffrey C. Innovative strategies for the management of long bone infection. A review of Masquelet technique. Patient Saf Surg 2015;9:32.

[6] Meister K, Segal D, Whitelaw GP. Role of bone grafting in the treatment of delayed unions and non-unions of the tibia. Orthop Rev 1990;19(3)260-71.

[7] Motsitsi NS. Management of infected non-union of long bones. The last decade (1996-2006). Injury 2008;39(2):155-60.

[8] Giannoudis PV, Faour O, Goff T, et al. Masquelet technique for the treatment of bone defects: trips and tricks and future directions. Injury 2011;42(6):591-8.

[9] Toh CL, Jupiter JB. The infected non-union of the tibia. Clin Ortho Relat Res 1995;(315):176-91.

[10] Wong TM, Lau TW, Xin Li, et al. Masquelet technique for treatment of posttraumatic bone defects. Article ID 710302, The Scientific World Journal 2014;2014: p. 5.

[11] Shahcheraghi GH, Bayatpoor A. Infected tibial nonunion. Can J Surg 1994;37(3):209-13.

[12] Dhanasekhar R, Jacob PJ, Francis J. Antibiotic cement impregnated nailing in the management of infected non-union of femur and tibia. Kerala Journal of Orthopaedics 2013;26(2):93-7.

[13] Shyam AK, Sancheti PK, Patel SK, et al. Use of antibiotic cement-impregnated intramedullary nail in treatment of infected non-union of long bones. Indian Journal of Orthopaedics 2009;43(4):396-402.

[14] Bhatia C, Tiwari AK, Sharma SB, et al. Role of antibiotic cement coated nailing in infected non-union of tibia. Malaysian Orthopaedic Journal 2017;11(1):6-11. 